\title{
Measurement Report: A Multi-Year Study on the Impacts of Chinese New Year Celebrations on Air Quality in Beijing, China.
}

Benjamin Foreback ${ }^{1,2}$, Lubna Dada², Kaspar Dällenbach ${ }^{2}$, Chao Yan ${ }^{1,2}$, Lili Wang ${ }^{3}$, Biwu Chu ${ }^{2,4}$, Ying Zhou ${ }^{1}$, Tom V. Kokkonen ${ }^{2,6}$, Mona Kurppa ${ }^{7}$, Rosaria E. Pileci ${ }^{5}$, Yonghong Wang ${ }^{2}$, Tommy Chan ${ }^{2}$, Juha Kangasluoma ${ }^{1,2}$, Lin Zhuohui ${ }^{1}$, Yishou Guo ${ }^{1}$, Chang Li ${ }^{1}$, Rima Baalbaki ${ }^{2}$, Joni Kujansuu ${ }^{1,2}$, Xiaolong Fan ${ }^{1}$, Zemin Feng ${ }^{1}$, Pekka Rantala ${ }^{2}$, Shahzad Gani ${ }^{2}$, Federico Bianchi ${ }^{1,2}$, Veli-Matti Kerminen ${ }^{2}$, Tuukka Petäjä ${ }^{1,2,6}$, Markku Kulmala ${ }^{1,2,6}$, Yongchun Liu ${ }^{1}$ and Pauli Paasonen ${ }^{1,2}$

${ }^{1}$ Aerosol and Haze Laboratory, Beijing Advanced Innovation Center for Soft Matter Science and Engineering, Beijing University of Chemical Technology, Beijing, China

${ }^{2}$ Institute for Atmospheric and Earth System Research / Physics, Faculty of Science, University of Helsinki, Finland

${ }^{3}$ Institute of Atmospheric Physics, Chinese Academy of Sciences, Beijing, China

${ }^{4}$ State Key Joint Laboratory of Environment Simulation and Pollution Control, Research Center for EcoEnvironmental Sciences, Chinese Academy of Sciences, Beijing 100085, China

${ }^{5}$ Laboratory of Atmospheric Chemistry, Paul Scherrer Institute (PSI), 5232 Villigen, Switzerland

${ }^{6}$ Joint International Research Laboratory of Atmospheric and Earth System Sciences, School of Atmospheric Sciences, Nanjing University, Nanjing, China

${ }^{7}$ Atmospheric Composition Research, Finnish Meteorological Institute, Helsinki, Finland

Corresponding Author: Pauli Paasonen (pauli.paasonen@helsinki.fi)

\begin{abstract}
We investigated the influence of the Chinese New Year (CNY) celebrations on local air quality in Beijing from 2013 through 2019, bringing together comprehensive observations at the newly-constructed Aerosol and Haze Laboratory at Beijing University of Chemical Technology - West Campus (BUCT-AHL) and data from Chinese government air quality measurement stations. In this study, these datasets are used together to provide a detailed analysis of air quality during the CNY over multiple years. Before CNY in 2018, the city of Beijing prohibited the use of fireworks and firecrackers in an effort to reduce air pollution. In 2018 air pollutant concentrations still showed a significant peak during the CNY night, even though not as strong as in previous years, but in 2019, the pollution levels were notably lower. During the studied 7-year study period, it appears that there has been a long-term decrease in CNY related emissions since 2016. Based on our analysis, the pollutants with the most notable spike during CNY were sulfur dioxide and particulate matter, including black carbon. Sulfuric acid concentration followed the sulfur dioxide concentration and showed elevated overnight concentration in CNY 2018, but not notably in 2019. Additionally, spectrometer data and analysis of aerosol particle number size distribution shows direct emissions of particles with diameters around $20 \mathrm{~nm}$ during CNY in 2018 and 2019. Meteorological conditions were comparable between the latest two years, indicating that air quality associated with the CNY may be improving, perhaps a positive effect of the restrictions. The longer observations in the future will provide confirmation for these trends.
\end{abstract}

\section{INTRODUCTION}

Anthropogenic emissions associated with festivities, notably fireworks and firecrackers (hereafter simply fireworks), are known for their hazardous effects, and even short-term exposure can have significant impacts on human health (Bach et al., 2007; Chen et al. 2011; Jiang et al. 2015; Yang et al. 2014). Firework celebrations 


\begin{abstract}
are found to increase the concentrations of trace gases and particle concentrations (Kong et al. 2015; Li et al. 2013). Furthermore, some studies have related these festivities to the occurrence of haze episodes in the days following a firework event ( $\mathrm{Li}$ et al. 2013; Feng et al. 2012).
\end{abstract}

The CNY is a traditional annual holiday occurring in wintertime - in January or February (the exact date is based on the lunar cycle). Because of the adverse impacts on health, pollution from fireworks during the CNY has gathered attention worldwide. For instance, studies including Yang et al. (2014) in Jinan, Shi et al. (2014) in Tianjin, and Feng et al. (2012) and Zhang et al. (2010) in Shanghai have shown that there is noticeable degradation in air quality associated with Chinese New Year celebrations in these cities. The effects of fireworks on air pollution are known for various holidays in other countries as well. Studies in India, for example, during the country's annual Diwali Festival in the late autumn have also shown results of high pollution from firework use (Ravindra et al. 2003; Mönkkönen et al. 2004; Barman et al. 2007; Singh et al. 2009; Yerramesetti et al. 2013). As another example, a study by Liu et al. (1997) in Southern California, USA showed enhanced concentrations of particulate matter and trace gas pollutants during firework celebrations.

Beginning in 2018, a prohibition on firework burning within the $5^{\text {th }}$ Ring Road of Beijing was implemented (Liu et al. 2019). The study by Liu et al. (2019) reported that the prohibition resulted in about a $40 \%$ decrease in the total number of fireworks and firecrackers sold in Beijing around the $2018 \mathrm{CNY}$ compared to 2016. Furthermore, the amount of toxic pollution during the 2018 CNY was significantly less than that in 2016.

In this study, we focus on the measurements collected from the Beijing University of Chemical Technology, Aerosol and Haze Laboratory (BUCT-AHL, Liu et al., 2020), an academic research station in Beijing China, along with seven years of data from the Chinese Ministry of Environmental Protection (MEP) throughout the Beijing metropolitan area. The long-term datasets also provide spatial context in the scale of the greater Beijing area, including a comparison of measurements inside versus outside of the prohibition area. Here we investigated years 2013-2019. The $2020 \mathrm{CNY}$ has not been included in this study because of the widespread impacts of the COVID-19 virus that affected China during this time. Due to the unfortunate circumstance, many Chinese citizens refrained from travel, public celebrations, and time spent in public. Consequently, the 2020 CNY is not directly comparable to previous years.

The aim of this this paper is to provide a detailed view on how CNY celebrations have influenced air quality, atmospheric chemistry and gas-to-particle conversion in Beijing. We start with an in-depth analysis of data from 2018 and 2019 while the longer, 7-year data set provides the perspective into the impacts of the imposed restrictions on firework use in the Beijing area. The specific questions we aim to answer include: i) how do the CNY celebrations and associated increase in precursor and aerosol emissions reflect into the atmospheric concentrations of trace gases and particulate matter and particle number size distribution; ii) how are these changes connected with meteorological conditions; iii) how does the influence of CNY to regional air quality vary spatially over the Beijing area; iv) how the influence of CNY on Beijing air quality has changed during the recent years, including the result of the firework prohibition beginning in 2018; and v) how does the gas phase sulfuric acid relate to the new particle formation and cluster mode particle number concentration during CNY. Our insights are useful for scientists and policy makers around the world who are interested in improving air quality during holidays that involve firework celebrations. Improving air quality, even short-term, could have a significant positive impact on health and wellbeing of citizens.

\title{
2 METHODS
}

\subsection{Measurement sites}


Data collected for this study have been measured at the newly constructed station near the third ring road of Beijing (39 56'N, 116 17'E; Figure 1, Liu et al., 2020). The station, known as the Aerosol and Haze Laboratory, is located on Beijing University of Chemical Technology West Campus, which is a five-floor building nearby to a busy highway. The station, hereafter BUCT-AHL, is following the concept of the Station for Measuring Ecosystem-Atmosphere Relations (SMEAR) in Hyytiälä, Southern Finland (Hari and Kulmala, 2005). BUCTAHL was built in collaboration with the Institute of Atmospheric and Earth System Research (INAR) at the University of Helsinki as part of the effort to build a global SMEAR network (Kulmala, 2018), with the aim to understand atmospheric chemical cocktail in megacity (Kulmala, 2015).

In our analysis the following datasets from BUCT-AHL during the 2018 and 2019 CNY are used: 1) Trace gas concentrations: nitrogen oxides $\left(\mathrm{NO}_{\mathrm{X}}\right)$, sulfur dioxide $\left(\mathrm{SO}_{2}\right)$, ozone $\left(\mathrm{O}_{3}\right)$, and carbon monoxide $\left.(\mathrm{CO}), 2\right) \mathrm{PM} 2.5$ aerosol mass concentration, 3) Black carbon mass concentration (BC), 4) Sub-micron aerosol particle number size distributions, 5) Gas-phase sulfuric acid $\left(\mathrm{H}_{2} \mathrm{SO}_{4}\right)$ concentration, 6) Meteorological observations.

Additionally, datasets from several national air quality monitoring sites (NAQMS; Song et al. 2017; Tao et al. 2016) within Beijing obtained from the Chinese Ministry of Environmental Protection (MEP) were utilized as follows: 1) Fine and coarse particulate matter mass concentrations (PM2.5 and PM10), 2) trace gases (NOX, SO2, O3, and CO) from 2013 through 2019 for a multi-year comparison. This also provided insights into the spatial variability within the Beijing city and particularly contrasting the area, where the ban for the fireworks was implemented against the urban background air quality.

\subsection{Instrumentation}

\subsubsection{Observations in BUCT-AHL station}

\section{Trace gas measurements}

Concentrations of carbon monoxide $(\mathrm{CO})$, sulfur dioxide $\left(\mathrm{SO}_{2}\right)$, ozone $\left(\mathrm{O}_{3}\right)$ and nitrogen oxides $\left(\mathrm{NO}_{\mathrm{x}}\right)$ were measured with Thermo Environmental Instruments models 48i, 43i-TLE, 42i, and 49i, respectively. They were all sampled through a common inlet through the roof of the building. The length of the sampling tube was approximately $3 \mathrm{~m}$ long (Zhou et al. 2020). The time resolution of the measurements was 5 minutes, but to be consistent with the MEP datasets, one hour averages were used in this study.

\section{Meteorological observations}

Meteorological datasets were collected with a Vaisala automatic weather station, AWS310 on the rooftop of BUCT-AHL including wind speed and direction, ambient air temperature and relative humidity. Boundary layer height was measured using a Vaisala CL-51 ceilometer on the rooftop of BUCT-AHL.

\section{Sub-micron aerosol particle number size distributions and total number concentrations}

Particle size distribution between $3 \mathrm{~nm}$ and $1 \mu \mathrm{m}$ was measured using a particle size distribution (PSD) (Liu et al., 2016). The PSD is composed of a nano-scanning mobility particle sizer (nano-SMPS, 3-55 nm, mobility diameter), a long SMPS (25-650 nm, mobility diameter) and an aerodynamic particle sizer (APS, $0.55-10 \mu \mathrm{m}$, aerodynamic diameter). It was fitted with a cyclone to remove particles larger than $10 \mu \mathrm{m}$ from entering the system. Sampling was done from the rooftop using a $3 \mathrm{~m}$ long sampling tube. Additional information about the setup of these instruments can be found in Zhou et al. (2020). nucleation mode (3-25 nm), Aitken mode (25-100 nm), and accumulation mode (100-1000 nm). The method of is described in Zhou et al. (2020). 
Furthermore, at BUCT-AHL, aerosol particle number size distribution of aerosol particles from 2.5 to $42 \mathrm{~nm}$ was measured with a neutral cluster and air ion spectrometer (NAIS; model 4-11, Airel, Estonia; Manninen et al., 2016; Mirme and Mirme, 2013). The NAIS sampled outside air from a horizontally oriented, $4 \mathrm{~cm}$ diameter copper sampling tube extending $1.6 \mathrm{~m}$ out of a north-facing window. The sampling flow rate was $541 \mathrm{~min}^{-1}$ (Zhou et al., 2020).

150

Additionally, an Airmodus A11 Nano Condensation Nucleus Counter (nCNC) system, commonly known as PSM (Vanhanen et al., 2011) was used to measure the sub $3 \mathrm{~nm}$ particle number concentration. The PSM was operated in scanning mode in which the saturator flow is continuously ramped between 0.1 and $1.3 \mathrm{lpm}$ and back to $0.1 \mathrm{lpm}$. The sampling line was $1.2 \mathrm{~m}$ long and having the same orientation as the NAIS sampling line.

\section{Gas-phase sulfuric acid}

Sulfuric acid was measured by a chemical ionization atmospheric-pressure interface time-of-flight mass spectrometer equipped with a nitrate chemical ionization source (CI-APi-TOF, Jokinen et al., 2012). The ionization was done with NO3- as the reagent ion in ambient pressure (e.g., Petäjä et al., 2009). Nitrate reagent ion was produced by photo-ionizing a mixture of $3 \mathrm{~mL} \cdot \mathrm{min}^{-1}$ ultrahigh purity nitrogen flow containing nitric acid with $20 \mathrm{~mL} \cdot \mathrm{min}^{-1}$ zero air. This mixture acted as the sheath flow and was introduced into a coaxial laminar flow reactor concentric to the sample flow. The sample flow was $8.8 \mathrm{~L} \mathrm{~min}^{-1}$ but only $0.8 \mathrm{~L}$. $\mathrm{min}^{-1}$ was drawn into the pinhole of the TOF. The sampling line was $1.6 \mathrm{~m}$ long stainless-steel tube having an inner diameter of 3/4 inch and positioned horizontally. The instrument was calibrated with known concentrations of sulfuric acid. Further information about the calibration procedure can be found in Kürten et al. 2012.

\section{Black carbon mass concentration}

An aethalometer AE33 (Magee Scientific) monitored the light absorption related to the aerosol. Equivalent black carbon $(\mathrm{eBC})$ was computed based on the change in time of the light attenuation using procedures presented in Virkkula et al. (2015)

\subsubsection{Chinese MEP Data}

Beginning in 2013, the Chinese Ministry of Environmental Protection began installing sensors China-wide to measure local, regional, and large-scale air quality. Real-time datasets from this sensor network are published hourly by the China Environmental Monitoring Center (CEMC), which includes $\mathrm{PM}_{10}, \mathrm{PM}_{2.5}, \mathrm{SO}_{2}, \mathrm{NO}_{\mathrm{x}}$ and CO. There are over 1000 active sensors across China (Song et al. 2017; Tao et al. 2016).

In this study, data from 12 MEP sites throughout Beijing are used (See Table 1 in Supplementary Information for a list of these sites and their locations). The Guanyuan (GY) site is the closest site to BUCT-AHL, about 5 $\mathrm{km}$ east. The original data are available at http://106.37.208.233:20035/ and for this study we have removed the outliers with criteria presented by $\mathrm{Wu}$ et al. (2018).

\section{RESULTS AND DISCUSSION}

Effects of elevated pollutant emissions during the Chinese New Year were observed both at BUCT-AHL and the MEP sites during the analysis periods. Effects include sudden spikes in concentrations of trace gases, particles, and BC. We explore the time series of the observations in the section below in more detail.

\subsection{Characteristics of air quality during the Chinese New Year}


Figure 2 shows a timeseries of air pollutant concentrations from eight days before to eight days after the 2018 and $2019 \mathrm{CNY}$ at BUCT-AHL. The CNY was on February 16, 2018 and February 5, 2019. In the BUCT measurements, we observed sharp peaks in Particulate Matter mass $\left(\mathrm{PM}_{2.5}\right), \mathrm{SO}_{2}$, sulfuric acid, $\mathrm{CO}, \mathrm{BC}, \mathrm{NO}$, and $\mathrm{NO}_{2}$ and ozone during firework events. These observations agree with the previous studies showing a connection between holiday-related firework celebrations and degraded air quality (Jiang et al., 2015; Yang et al., 2014; Shi et al., 2014; Feng et al., 2012; Zhang et al., 2010).

Figure 2 shows that in 2018, a significant spike in $\mathrm{PM}_{2.5}$ concentration is observed overnight, in particular at midnight, on the CNY. Additionally, in 2018 period of haze for three days following the CNY was observed. In contrast, in 2019, $\mathrm{PM}_{2.5}$ was observed to have lower concentration on the CNY night than on the previous and following nights. There is also a noticeable spike in $\mathrm{SO}_{2}$ overnight of the CNY in 2018, shown in Figure 3 , but less noticeable alteration of $\mathrm{SO}_{2}$ is observed overnight of the $2019 \mathrm{CNY}$.

The measurements show clearly elevated nighttime concentration of $\mathrm{H}_{2} \mathrm{SO}_{4}$ on $\mathrm{CNY}$ in 2018 , concentration exceeding $3 * 10^{6} \mathrm{~cm}^{-3}$ during the whole night, whereas on other nights such high concentrations are observed only occasionally. In 2019, there is no signs of anomalies in nighttime $\mathrm{H}_{2} \mathrm{SO}_{4}$ concentration during CNY. An unknown spike in $\mathrm{H}_{2} \mathrm{SO}_{4}$ is noticed at noon the day before $\mathrm{CNY}$ in 2018, and its association with celebratory activities is unclear. Like with $\mathrm{PM}_{2.5}$ and $\mathrm{SO}_{2}$, Figure 2 shows a clearly distinctive spike in BC around midnight of the 2018 CNY. However, there appears to be little to no effect of CNY on BC in 2019.

The measurements show elevated concentration of $\mathrm{NO}_{2}$ overnight of the CNY in both years, yet no spike in $\mathrm{NO}$ concentration. Fireworks emit $\mathrm{NO}_{2}$ but not $\mathrm{NO}$ (Jiang et al., 2015); however, a high $\mathrm{NO}_{2} / \mathrm{NO}_{\mathrm{x}}$ ratio can also be caused by accumulation of pollutants emitted the previous afternoon (Chou et al., 2009). Nonetheless, when comparing the $\mathrm{CNY}$ characteristics of $\mathrm{NO}_{\mathrm{x}}$ with other pollutants, there is a noticeable spike of $\mathrm{NO}_{2}$ during the CNY during both years.

Generally, Figure 2 shows that during the CNY celebrations in 2018 concentrations of all the primary pollutants are elevated, implying enhanced direct emissions. The concentrations of sulfuric acid and ozone react to elevated concentrations as expected, sulfuric acid concentration increases due to enhanced formation with increased $\mathrm{SO}_{2}$ concentration, and ozone concentration decreases with increased chemical sink by $\mathrm{NO}_{\mathrm{x}}$ and $\mathrm{CO}$ (and probably other carbon compounds). However, on 2019, only the concentrations of $\mathrm{CO}$ and $\mathrm{NO}_{2}$ are observed to increase during CNY celebrations, leading to decrease in ozone concentration, whereas the concentrations of all other pollutants did not show elevated concentrations. Interestingly, the measurements in Figure 2 show degraded air quality between 16-20 February 2018 immediately following the Chinese New Year, which closely resembles the characteristics of a haze event as described in Zhao et al. (2013) and Zhao et al. (2011). These haze events have elevated concentrations of pollution continuously for multiple days, and these concentrations gradually increase throughout the episodes, and they end with sudden decline, often caused by a cold front or synoptic weather system. Several previous studies, including Jiang et al. (2015) and Li et al. (2013), suggest that fireworks likely contribute to haze formation. Therefore, the increased level of pollutants observed overnight during the $2018 \mathrm{CNY}$ have likely contributed to this subsequent haze period. However, the meteorological conditions are also important for haze formation, which are discussed in Section 3.2.

\subsection{Effects of Meteorology and Boundary Layer Height}

Because meteorology conditions vary between different years, it is important to understand its effects on pollution when comparing different years to each other. Most notably, wind, humidity, boundary layer height, and precipitation can affect pollutant concentrations during and after the fireworks. 
The wind speed during the night of the $2018 \mathrm{CNY}$ peaks at $\sim 2 \mathrm{~m} / \mathrm{s}$, whereas during the night of the $2019 \mathrm{CNY}$, it remains less than $\sim 1 \mathrm{~m} / \mathrm{s}$. Temperature and relative humidity are quite comparable between the years. Precipitation was not measured at BUCT-AHL in either year. However, online weather data shows there was no precipitation in the region during either of the years (https://www.wunderground.com/history/weekly/cn/beijing/ZBNY/date/2019-2-4). The nocturnal boundary layer heights are low in both years (Figure 2), which is unfavorable for vertical mixing of pollutants. This, along with the low wind speeds, points towards more efficient dispersion in pollutant concentrations in 2018 than in 2019, indicating that the reason for clearly lower pollutant concentrations in 2019 is likely related to lower emissions, not meteorological conditions.

\subsection{Particle number concentrations and size distribution}

To further explore the effects the fireworks on air pollution, Figure 3 shows particle number concentrations and size distributions measured by the NAIS instrument at BUCT-AHL from the day before to the day after CNY. The results show that shortly before midnight on CNY in 2018, an elevated concentration of aerosol particles with diameters of roughly $20 \mathrm{~nm}$ was observed, simultaneous to the spike in $\mathrm{SO}_{2}$ concentration. This increase in particle number concentration is not associated with a regional new particle formation (NPF) event (e.g. Mäkelä et al., 1997; Shen et al., 2011; Heintzenberg et al. 2007), which in this case is taking place on the following day before noon, where the concentrations of well below $10 \mathrm{~nm}$ particles are first observed to increase and then to grow to $20 \mathrm{~nm}$ sizes. This feature suggests that the observed particles during festivities are of primary origin and emitted to atmosphere in the respective size range, possibly from the fireworks. Similar to most other pollutants, particle number concentrations in this size range in CNY 2019 do not show signs of celebration related emissions. There is a continuous concentration of particles in the respective size range, but no clear peaks during the celebrations, in line with no signs of increased $\mathrm{SO}_{2}$ concentration.

Aerosol particle mass concentration (PM2.5) during the CNY firework period is clearly elevated reaching values close to $250 \mu \mathrm{g} \mathrm{m}^{-3}$ and $150 \mu \mathrm{g} \mathrm{m}^{-3}$ at midnight for the year 2018 and 2019, respectively, which are considerable higher than the mass concentrations on the previous day. The midnight peak in PM mass concentration coincides with atmospheric nanoparticle concentrations and elevated $\mathrm{SO}_{2}$ in 2018 indicating high emissions of primary aerosol particles and co-emitted sulfur dioxide.

Figure 4 shows the particle number concentrations in four size modes, namely sub-3 nm cluster mode, 3-25 nm nucleation mode, 25-100 nm Aitken mode, and 100-1000 nm accumulation mode, as a function $\mathrm{PM}_{2.5}$ concentration measured at BUCT-AHL in 2018 and 2019, for 48 hours before through 48 hours after the CNY. The darker colors mark the nighttime measurements on the CNY (9pm-5am). The night-time mass concentrations are noticeably greater. The mass-to-number concentration comparison follows the same general curve during nighttime as the full time period, and the pattern, including the nighttime observations, is consistent with recent investigation by Zhou et al. (2020). The $\mathrm{PM}_{2.5}$ concentrations during the CNY period in 2018 are significantly higher than in other periods. The cluster and nucleation mode concentrations are lower, Aitken mode is on the same level, and accumulation mode concentration is higher during the CNY period. This is reasonable, as accumulation mode particles contribute significantly to PM2.5 mass and constitute the major sink for cluster and nucleation mode particles due to coagulation scavenging of smaller particles by larger ones.

In figure 5 we can see how the cluster mode concentrations behaves as a function of sulfuric acid. The high nocturnal sulfuric acid concentration during CNY celebrations in 2018 do not lead to high cluster or nucleation mode concentration. In fact, the particle number concentrations in these modes deviates from the otherwise clear response to sulfuric acid concentrations. The reason for this is visible in the panel for accumulation mode concentration vs sulfuric acid concentration: during the CNY 2018 the high concentrations of accumulation 
mode particles correlates with sulfuric acid concentration thus plausibly neglecting the enhanced particle cluster and particle formation rates by enhanced coagulation sink as explained earlier.

\subsection{Multi-Year Variation of Chinese New Year Effects in Beijing}

Although fireworks were formally prohibited within the $5^{\text {th }}$ Ring Road of Beijing beginning in 2018, there was still evidence of fireworks burning either in the city or the immediate vicinity of the city, as measured at BUCTAHL, which is within the prohibition area. Nonetheless, because the initial peak during the $2018 \mathrm{CNY}$ (Figure 6 ) is significantly higher, even though it disperses more quickly, it is therefore evident that there was more initial pollution during this time, whereas the amount of pollution during the $2019 \mathrm{CNY}$ was considerably less, even though it remained present for longer time period.

A longer-term multi-year study can be useful in demonstrating whether or not the policy is effective in reducing firework-related pollution, and if there is an overall decreasing trend of pollution effects from fireworks over multiple years. To investigate this question, it is useful to compare the 2018 and 2019 CNY with previous years in Beijing. Datasets have been analyzed from 12 stations in Beijing from 2013 through 2019.

Figure 6 shows that each year, there was a spike in pollution around midnight during the CNY. The highest levels were observed in 2016, and the lowest levels were in 2019. Observations from 2013, 2014, 2015, and 2017 also showed similarly high or higher levels of $\mathrm{PM}_{2.5}$ as in 2018 (unfortunately the 2017 dataset is incomplete and does not extend beyond 00:00 of New Year day). Furthermore, data from 2013, 2014, 2015 and 2018 suggest the presence of haze episodes in the days following the New Year, potentially related to firework burning. An elevated level of pollution for two days after the CNY compared to before the CNY was observed in 2019 as well, even though it was to a lesser extent.

Data from the CNYs have also been compiled into box plots in Figure 7, depicting the distributions of pollutant concentrations from 6:00 pm on CNY Eve to 6:00 am on the CNY day each year. The highest PM concentrations during this time were in 2016 and have since decreased. Concentrations of $\mathrm{NO}_{2}, \mathrm{SO}_{2}$, and $\mathrm{CO}$ all show a similar pattern as PM. It should be noted that in 2017 , the data is missing after midnight. The decrease since 2016 agrees with the results obtained by Liu et al. 2019. Since ozone is a secondary product and it reacts with several primary pollutants, its concentration pattern being roughly opposite to those of primary pollutants is as expected. In this aspect, it is notable that in 2019 in addition to primary pollutant concentrations also ozone concentration has decreased from 2017 and 2018.

\subsection{Spatial variability based on MEP measurement network data}

A further analysis of the CNY in Beijing is to perform a spatial comparison of the MEP measurements across the Beijing region. This includes comparing the observations inside the $5^{\text {th }}$ Ring Road, where fireworks were prohibited, to outside the ring. Figure 8 maps the 12 MEP stations in the Beijing region for 2013-2019, showing the relative difference of $\mathrm{PM}_{2.5}$ measurements from $9 \mathrm{pm}$ through 5 am during the night of CNY to the average of measurements \pm 48 hours of the CNY at each site. Figures in Supplementary Information show observations of $\mathrm{PM}_{2.5}$ from the 12 individual MEP sites and the corresponding differences, year-by-year from 2013-2019. Based on Figure 8, we can see significant variation from year to year as to which station measures the highest pollution. It is important to note that the population density is greater closer to city center, and thus the population density could impact the results. However, it is plausible to assume that the relative population density difference between the city center and the surrounding areas do not change dramatically during the few year time period. 
Figure 8 illustrates that in 2013 and 2014, the enhancement in $\mathrm{PM}_{2.5}$ concentrations during CNY is greater inside the $5^{\text {th }}$ ring than outside. In 2015, the enhancement is much greater at the two northeastern sites (HR and SY). In 2016, the differences vary, with no clear difference inside or outside the $5^{\text {th }}$ ring. In 2018 , the enhancement of $\mathrm{PM}_{2.5}$ is higher inside the $5^{\text {th }}$ ring than outside, except for the SY site to the far northeast, which had significantly high enhancement compared to the other sites. In 2019 the enhancement is overall less inside compared to outside.

Figure 9 shows differences between the $\mathrm{PM}_{2.5}$ median of the sites inside the $5^{\text {th }}$ Ring Road and the median of the sites outside the $5^{\text {th }}$ Ring (that is the median of the 8 inside sites minus the median of the outside 4 stations) 48 hours before through 48 hours after the CNY for 2013-2019. In most years, there is a greater enhancement of $\mathrm{PM}_{2.5}$ inside than outside. However, in 2015, the opposite was true. In 2016, the first part of the CNY overnight had lower $\mathrm{PM}_{2.5}$ inside than outside, but that reversed a few hours later. In 2019, there was less $\mathrm{PM}_{2.5}$ inside than outside throughout the night of CNY.

\section{CONCLUSIONS}

This study confirms that CNY consistently impacts air quality in Beijing year-after-year. These results are consistent with previous studies that have linked the CNY (and other similar holiday celebrations involving firework burning around the world) to degraded air quality both locally and regionally. Our results suggest that the regulations to limit firework use have improved the air quality within the restriction zone inside the fifth ring road in Beijing since 2016.

Based on our observations at BUCT-AHL station in Beijing, in 2018, we detected clearly higher than typical night-time concentrations of particulate mass (PM2.5), particle number, trace gas and sulfuric acid concentrations during the CNY. The increase in sulfuric acid concentration did not lead to observed new particle formation, which is explained by simultaneously increasing condensation and coagulation sinks for clustering vapors and freshly formed particles, respectively. However, we observed appearance of particles with diameters of roughly $20 \mathrm{~nm}$ that seemed to be linked to enhanced sulfur dioxide concentrations. Based on the MEP data, the peaks in concentrations of different pollutants were noticeably lower than in the previous years. In 2019, a peak in pollution was observed overnight, but it was significantly lower than in 2018, while meteorological conditions were comparable in both years. The significant year-to-year variability depended presumably on the meteorological conditions, on new imposed regulations as well as on the fact that the CNY period is determined with a lunar calendar and therefore the exact CNY period varies from year-to-year. In 2013, 2014, and 2015, haze episodes lasting several days were observed immediately following the CNY. In 2016 and 2018 a moderate haze episode began one day following the CNY.

Comparing the level of increase in pollutant concentrations during CNY night inside and outside Beijing $5^{\text {th }}$ ring road (firework prohibition area) revealed that in 2019 the increase inside this area was smaller than outside. During most, but not all, of the previous CNYs, the increase in concentration was higher inside than outside. This was also the case in 2018. However, as also in previous years the ratio of inside and outside concentrations during CNY has varied, it is unclear if this is related to efficacy of the emission prohibition or, e.g., to larger scale air-mass movements. As absolute concentrations, our results show a decrease of CNY pollution within the prohibition area since 2016 and especially in 2019. This is in agreement with the previous Liu et al. 2019 study, which compared the 2016 and $2018 \mathrm{CNY}$ (before and after the prohibition took effect).

This long-term analysis, which combines BUCT data with multiple years of Chinese government data, demonstrates the importance of analyzing multiple data sources to determine overall trends, rather than making conclusions based on a single dataset. This also demonstrates the usefulness of long-term measurements. Therefore, we suggest ongoing measurements at both BUCT-AHL and MEP sites into multiple future years. 
The combination of the BUCT-AHL comprehensive observations together with the spatial variability provided by the MEP sites, we see excellent potential that can be utilized to investigate the changes in a) atmospheric chemistry - like ozone dynamics and sulfuric acid formation; b) atmospheric gas-to-particle conversion; c) boundary layer dynamics and d) air quality. Here we have investigated CNYs as case studies to get better insight how rapid changes in emissions will affect the previous four items.

\section{ACKNOWLEDGEMENTS}

The work is supported by Academy of Finland via Center of Excellence in Atmospheric Sciences (project no. 272041) and European Research Council via ATM-GTP 266 (742206). This research has also received funding from Academy of Finland (project no. 316114 \& 315203, 307537), Business Finland via Megasense-project, European Commission via SMart URBan Solutions for air quality, disasters and city growth, (689443), ERANET-Cofund as well as the Doctoral Programme in Atmospheric Sciences at the University of Helsinki. Partial support from the National Key R\&D Program of China (2016YFC0200500), and the National Natural Science Foundation of China (91544231 \& 41725020) is acknowledged. The authors also wish to acknowledge the Finnish Centre for Scientific Computing (CSC) - IT Center for Science, Finland, for computational resources.

\section{AUTHOR CONTRIBUTIONS}

All BUCT affiliated authors, plus KD, BC, YW, TC, and PR contributed to measurement collection at BUCT. LW provided the quality-controlled MEP data. BF, LD, KD, TP, FB and MK conceptualized and conducted the data analysis. TK, MoK, RP, and RB participated in the data analysis. TK and MoK provided the meteorology data. KD, TP, FB, PP and MK supervised the study. BF visualized the data and visualized the data and prepared the manuscript with contributions from all other authors. SG assisted with the data visualization and generating figures.

\section{COMPETING INTERESTS}

The authors declare that there are no conflicts of interest in this study.

\section{REFERENCES}

Bach, W., Daniels, A., Dickinson, L., Hertlein, F., Morrows, J., Margolis, S., and Dinh, V. D. (2007). Fireworks Pollution and Health. International Journal of Environmental Studies. 7,1975:183-192.

Barman, S. C., Singh, R., Negi, M. P. S., and Bhargava, S. K. (2007). Ambient air quality of Lucknow City (India) during use of fireworks on Diwali Festival. Environ. Monit. Assess., 137:495-504.

Chen, B., Kan, H., Chen, R., Jiang, S., and Hong, C. (2011). Air Pollution and Health Studies in China-Policy Implications. Journal of the Air \& Waste Management Association.65-11:1292-1299.

Chou, C. C.-K., Tsai, C.-Y., Shiu, C.-J., Liu, S. C., and Zhu, T. (2009). Measurement of NO during Campaign of Air Quality Research in Beijing 2006 (CAREBeijing-2006): Implications for the ozone production efficiency of $\mathrm{NO}_{\mathrm{x}}$. Journal of Geophysical Research: Atmospheres. 114:D00G01. 
Feng, J., Sun, P., Hu, X., Zhao, W., Wu, M., and Fu, J. (2012). The chemical composition and sources of $\mathrm{pm}_{2.5}$ during the 2009 Chinese new year's holiday in Shanghai. Atmospheric Research, 118:435-444.

Hari, P. and Kulmala, M. (2005). Station for Measuring Ecosystem-Atmosphere Relations (SMEAR II). Boreal Environment Research. 10:315-322.

He, H., Li, C., Loughner, C. P., Li, Z., Krotkov, N. A., Yang, K., Wang, W., Zheng, Y., Bao, X., Zhao, G., and Dickerson, R. R. (2012). SO2 over central China: Measurements, numerical simulations and the tropospheric sulfur budget. Journal of Geophysical Research, 117, D00K37.

Heintzenberg, J, Wehner, B., and Birmili, W. (2007). 'How to find bananas in the atmospheric aerosol': new approach for analyzing atmospheric nucleation and growth events. Tellus B: Chemical and Physical Meteorology, 59:2, 273-282.

Jiang, Q., Sun, Y. L., Wang, Z., and Yin, Y. (2015). Aerosol composition and sources during the Chinese Spring Festival: fireworks, secondary aerosol, and holiday effects. Atmospheric Chemistry and Physics, 15:6023-6034.

Kong, S. F., Li, L., Li, X. X., Yin, Y., Chen, K., Liu, D. T., Yuan, L., Zhang, Y. J., Shan, Y. P., Ji, Y. Q. (2015) The impacts of firework burning at the Chinese Spring Festival on

air quality: insights of tracers, source evolution and aging processes. Atmospheric Chemistry and Physics. 15:2167-2184.

Kulmala, M. (2015). Atmospheric Chemistry: China’s Chocking Cocktail. Nature Comment.

Kulmala, M. (2018). Build a global Earth observatory. Nature Comment.

Kürten, A., Rondo, L., Ehrhart, S., and Curtius, J. (2012). Calibration of a chemical ionization mass spectrometer for the measurement of gaseous sulfuric acid. The Journal of Physical Chemistry A. 116:63756386.

Li, W., Shi, Z., Yan, C., Yang, L., Dong, C., and Wang, W. (2013). Individual metal-bearing particles in a regional haze caused by firecracker and firework emissions. Sci. Total Environ, 443, 464-469.

Liu, D.-Y., Rutherford, D., Kinsey, M., and Prather, K. A. (1997). Real-Time Monitoring of Pyrotechnically Derived Aerosol Particles in the Troposphere. Analytical Chemistry, 69, 1808-1814.

Liu, J. Q., Jiang, J. K., Zhang, Q., Deng, J. G., and Hao, J. M. (2016). A spectrometer for measuring particle size distributions in the range of $3 \mathrm{~nm}$ to $10 \mu \mathrm{m}$, Frontiers of Environmental Science \& Engineering, 10:6372 .

Liu, J., Chen, Y., Chao, S., Cao, H., and Zhang, A. (2019). Levels and health risks of PM2.5-bound toxic metals from firework/firecracker burning during festival periods in response to management strategies. Ecotoxicology and Environmental Safety. 171:406-413.

Liu, Y.C., Yan, C., Feng, Z., Zheng, F., Fan, X., Zhang, Y., Li, C., Zhou, Y., Lin, Z., Guo, Y., Zhang, Y., Ma, L., Zhou, W., Liu, Z., Dada, L., Dällenbach, K., Kontkanen, J., Cai, R., Chan, T., Chu, B., Du, W., Yao, L., 
Wang, Y., Cai, J., Kangasluoma, J., Kokkonen, T., Kujansuu, J., Rusanen, A., Deng, C., Fu, Y., Yin, R., Li, X., Lu, Y., Liu, Y., Lian, C., Yang, D., Wang, W., Ge, M., Wang, Y., Worsnop, D.R., Junninen, H., He, H., Kerminen, V.-M., Zheng, J., Wang, L., Jiang, J., Petäjä, T., Bianchi, F. and Kulmala, M. (2020) Continuous and comprehensive atmospheric observation in Beijing: a station to understand the complex urban atmospheric environment, Big Earth Data 4, 295-321.

Manninen, H. E., Mirme, S., Mirme, A., Petäjä, T., and Kulmala, M. (2016). How to reliably detect molecular clusters and nucleation mode particles with Neutral cluster and Air Ion Spectrometer (NAIS), Journal of Atmospheric Measurement Techniques, 9:3577-3605, 10.5194/amt-9-3577-2016, 2016.

Mirme, S., and Mirme, A. (2013) The mathematical principles and design of the NAIS - a spectrometer for the measurement of cluster ion and nanometer aerosol size distributions. Journal of Atmospheric Measurement Techniques, 6:1061-1071, 2013.

Mönkkönen, P., Koponen, I.K., Lehtinen, K.E.J., Uma, R., Srinivasan, D., Hämeri, K., and Kulmala, M. (2004). Death of nucleation and Aitken mode particles: observations at extreme atmospheric conditions and their theoretical explanation. Journal of Aerosol Science. 35:781-787.

Peltonen, M. (2017). University of Helsinki builds an air quality measuring station in Beijing. University of Helsinki News and Press Releases.

Ravindra, K., Mor, S., and Kaushik, C. P. (2003). Short-term variation in air quality associated with firework events: A case study. Journal of Environ. Monit, 5. 260-264.

Shen, X. J., Sun, J. Y., Zhang, Y.M., Wehner, B., Nowak, A., Tuch, T., Zhang, X. C., Wang, T. T., Zhou, H. G., Zhang, X. L., Dong, F., Birmili, W., and Wiedensohler, A. (2011). First long-term study of particle number size distributions and new particle formations of regional aerosol in the North China Plain. Atmospheric Chemistry and Physics, 11:1565-1580.

Shi, G.-L., Liu, G.-R., Tian, Y.-Z., Zhou, X.-Y., Peng, X., and Feng, Y.-C. (2014). Chemical characteristic and toxicity assessment of particle associated PAHs for the short-term anthropogenic activity event: During the Chinese new year's festival in 2013. Science of the Total Environment, 482-483:8-14.

Singh, D. P., Gadi, R., Mandal, T.K., Dixit, C.K., Singh, K., Saud, T., Singh, N., and Gupta, P. K. (2009). Study of temporal variation in ambient air quality during Diwali festival in India. Environ. Monit. Assess, 169:1-13.

Song, C., Wu, L., Xie, Y., He, J., Chen, X., Wang, T., Lin, Y., Jin, T., Wang, A., Liu, Y., Dai, Q., Liu, B., Wang, Y., and Mao, H. (2017). Air pollution in China: Status and spatiotemporal variations. Environmental Pollution. 227:334-347.

Tao, M., Chen, L., Li, R., Wang, L., Wang, J., Wang, Z., Tang, G., and Tao, J. (2016). Spatial Oscillation of the particle pollution in eastern China during winter: Implications for regional air quality and climate. Atmospheric Environment.144:100-110. 
van der A, R. J., Mijling, B., Ding, J., Koukouli, M. E., Liu, F., Li, Q., Mao, H., and Theys, N. (2017) Cleaning up the air: effectiveness of air quality policy for $\mathrm{SO}_{2}$ and $\mathrm{NO}_{\mathrm{x}}$ emissions in China, Atmospheric Chemistry and Physics., 17:1775-1789.

Vanhanen, J., Mikkilä, J., Lehtipalo, K., Sipilä, M., Manninen, H. E., Siivola, E., Petäjä, T., and Kulmala, M. (2011). Particle Size Magnifier for Nano-CN Detection. Aerosol Science and Technology, 45:533-542, $10.1080 / 02786826.2010 .547889$.

Virkkula, A., Chi1, X., Ding, A., Shen, Y., Nie, W., Qi, X., Zheng, L., Huang, X., Xie, Y., Wang, J., Petäjä, T., and Kulmala, M. (2015). On the interpretation of the loading correction of the aethalometer. Atmospheric Measurement Techniques. 8:4415-4427.

532

Xue, W., Wang, J., Niu, H., Yang, J., Han, B., Lei, Y., Chen, H., and Jiang, C. (2013). Assessment of air quality improvement effect under the National Total Emission Control Program during the Twelfth National Five-Year Plan in China. Atmospheric Environment. 68:74-81.

Wu, H. J., Tang, X., Wang, Z. F., Wu, L., Lu, M. M., Wei, L. F., and Zhu, J. (2018). Probabilistic automatic outlier detection for surface air quality measurements from the China National Environmental Monitoring Network. Adv. Atmos. Sci., 35(12), 1522-1532.

540

Yang, L., Gao, X., Wang, X., Nie, W., Wang, J., Gao, R., Xu, P., Shou, Y., Zhang, Q., and Wang, W. (2014). Impacts of firecracker burning on aerosol chemical characteristics and human health risk levels during the Chinese New Year celebration in Jinan, China. Science of the Total Environment, 476-477:57-64.

Yerramsetti, V. S., Anu Rani Sharma, A. R., Navlur, N. G., Rapolu, V., Chitanya Dhulipala, N. S. K. C., and Sinha, P. R. (2013). The impact assessment of Diwali fireworks emissions on the air quality of a tropical urban site, Hyderabad, India, during three consecutive years. Environ. Monit. Assess., 185:7309-7325.

Zhang, M., Wang, X., Chen, J., Cheng, T., Wang, T., Yang, X., Gong, Y., Geng, F., and Chen, C. (2010). Physical characterization of aerosol particles during the Chinese new year's firework events. Atmospheric Environment, 44:5191-5198.

Zhao, X., Zhang, X., Pu, W., Meng, W., Xu, X. (2011). Scattering properties of the atmospheric aerosol in Beijing, China. Atmospheric Research. 101:799-808.

Zhao, X. J., Zhao, P. S., Xu, J., Meng, W., Pu, W. W., Dong, F., He, D., Shi, Q. F. (2013). Analysis of a winter regional haze event and its formation mechanism in the North China Plain. Atmospheric Chemistry and Physics. 13:5685-5696.

Zhou, Y., Dada, L., Liu, Y., Fu, Y., Kangasluoma, J., Chan, T., Yan, C., Chu, B., Daellenbach, K. R., Bianchi, F., Kokkonen, T. V., Liu, Y., Kujansuu, J., Kerminen, V.-M., Petäjä, T., Wang, L., Jiang, J., and Kulmala, M. (2020). Variation of size-segregated particle number concentrations in wintertime Beijing. Atmospheric Chemistry and Physics. 20:1201-1216 
https://doi.org/10.5194/acp-2021-192

Preprint. Discussion started: 20 May 2021

(c) Author(s) 2021. CC BY 4.0 License.

\section{Atmospheric \\ Chemistry and Physics \\ Discussions}

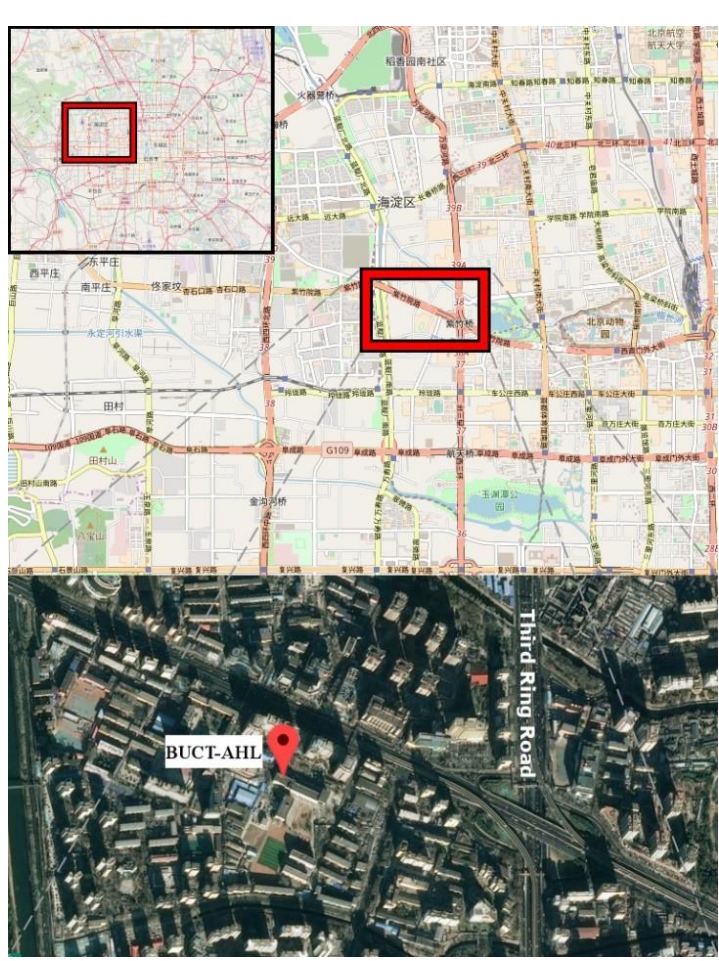

Figure 1: Location of the BUCT-AHL site within the Beijing metropolitan area. (C) OpenStreetMap contributors, CC BY-SA. 
https://doi.org/10.5194/acp-2021-192

Preprint. Discussion started: 20 May 2021

(C) Author(s) 2021. CC BY 4.0 License.
Atmospheric Chemistry and Physics

Discussions
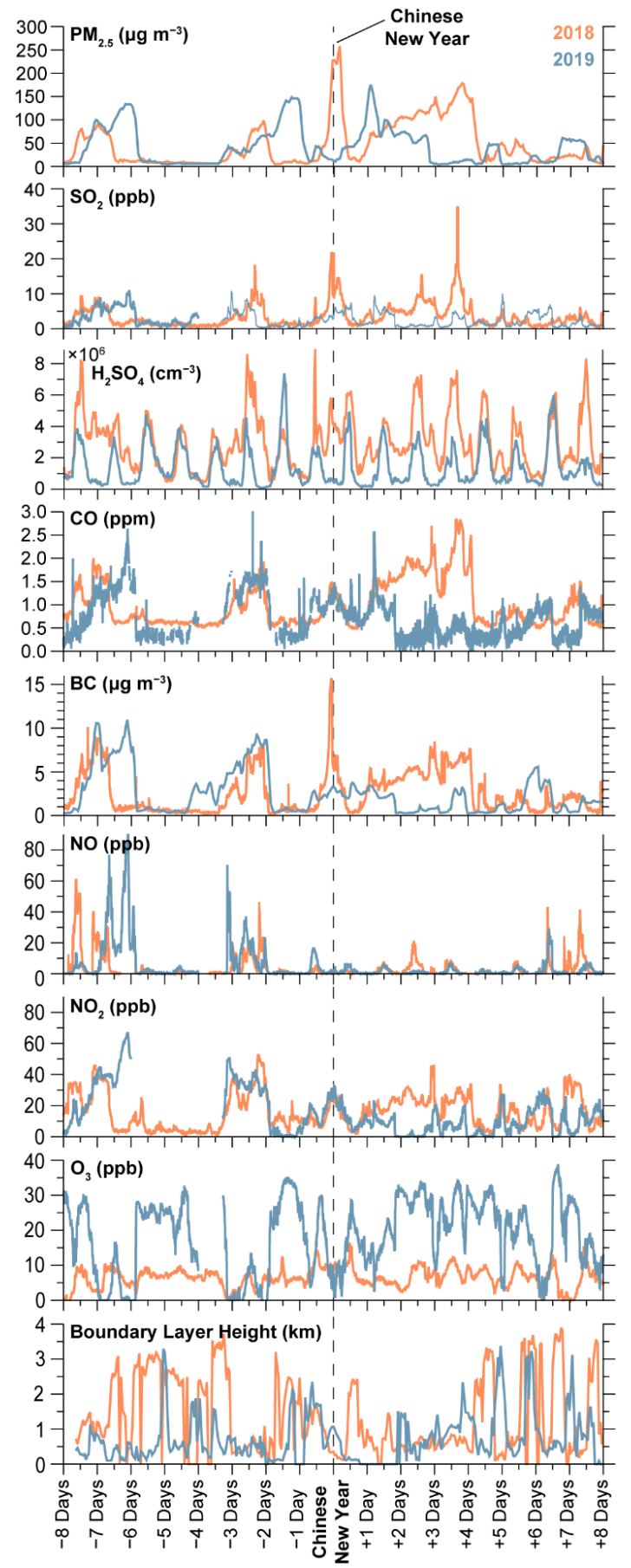

Figure 2: Major pollutants measured in Beijing during the 2018 and 2019 CNY. 
(a) 2018
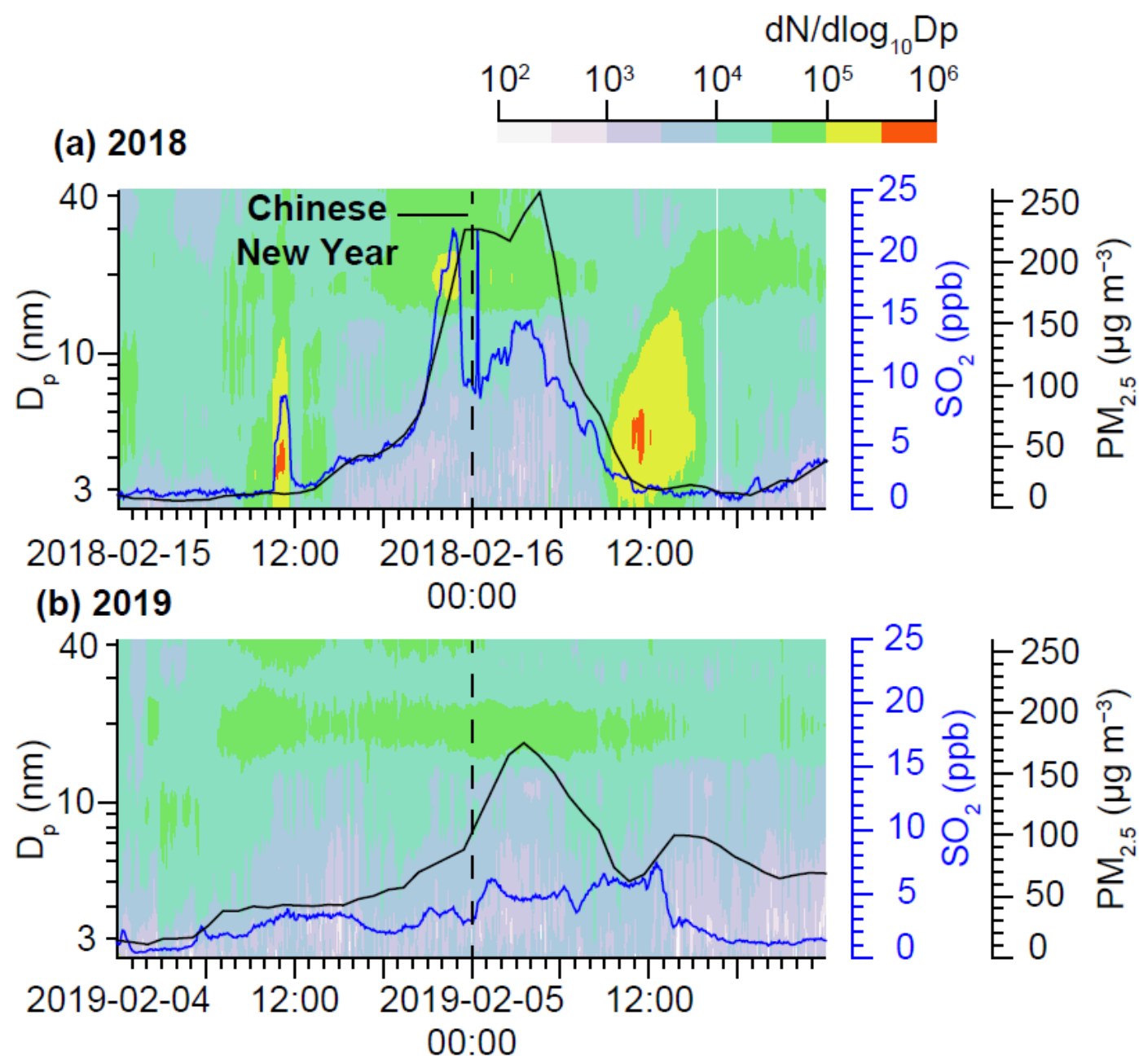

Figure 3: Aerosol number size distribution from NAIS instrument from one day before the CNY through one day following the CNY in 2018 and 2019, overlain with aerosol mass concentration $\mathrm{PM}_{2.5}$, black lines) and $\mathrm{SO}_{2}$ (blue lines). A spike of $\mathrm{PM}_{2.5}$ and $\mathrm{SO}_{2}$ is observed in both years, but significantly less in 2019. Results from the NAIS show a corresponding release of particles approximately $11 \mathrm{~nm}$ in diameter during the time of the CNY fireworks. 

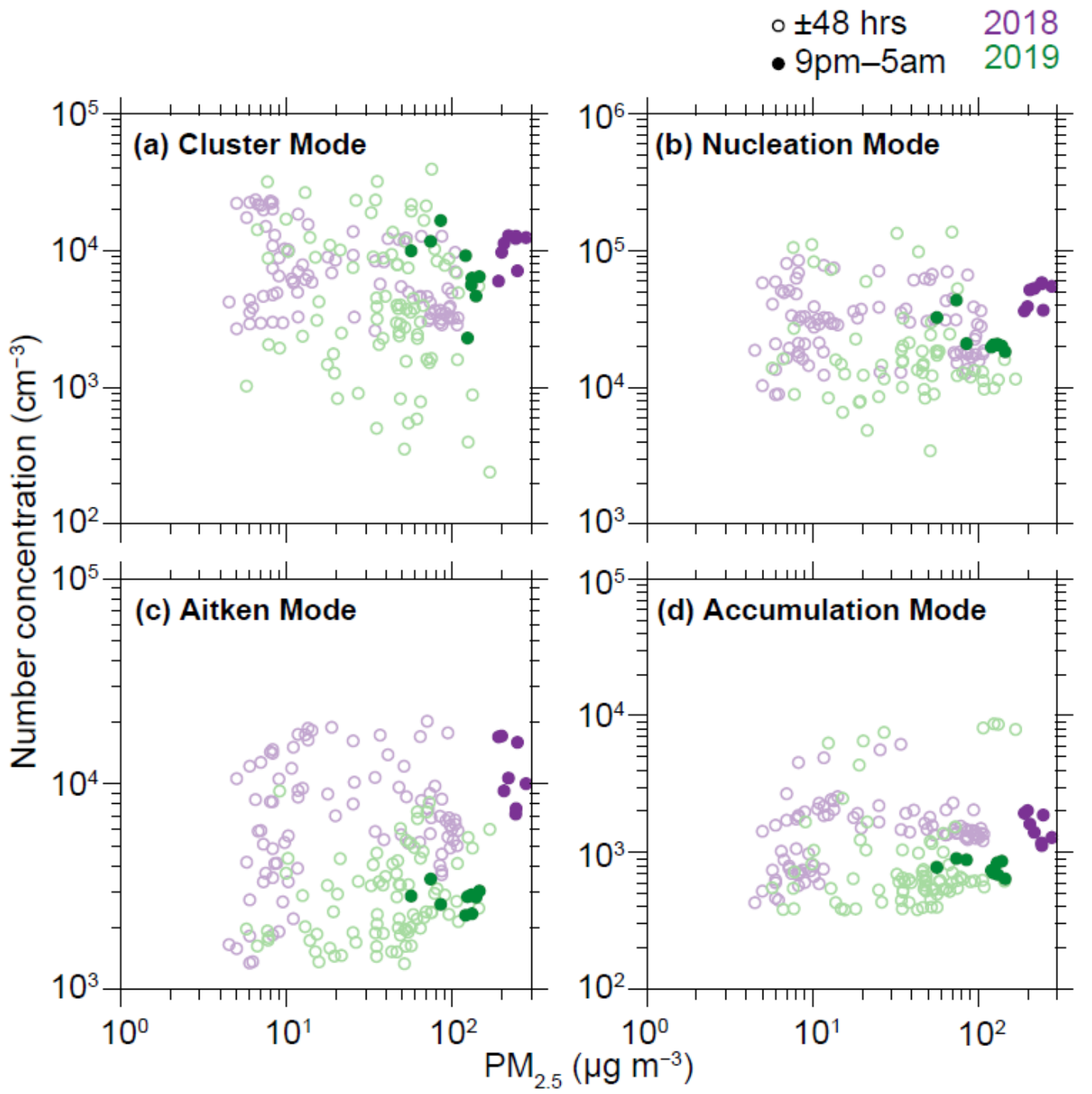

Figure 4: $\mathrm{PM}_{2.5}$ number concentration as a function of mass concentration in cluster, nucleation, Aitken, and accumulation modes in 2018 and 2019, with comparison of CNY \pm 48 hours with measurements from 9pm through 5am the night of the CNY. Measurements are from BUCT-AHL. 

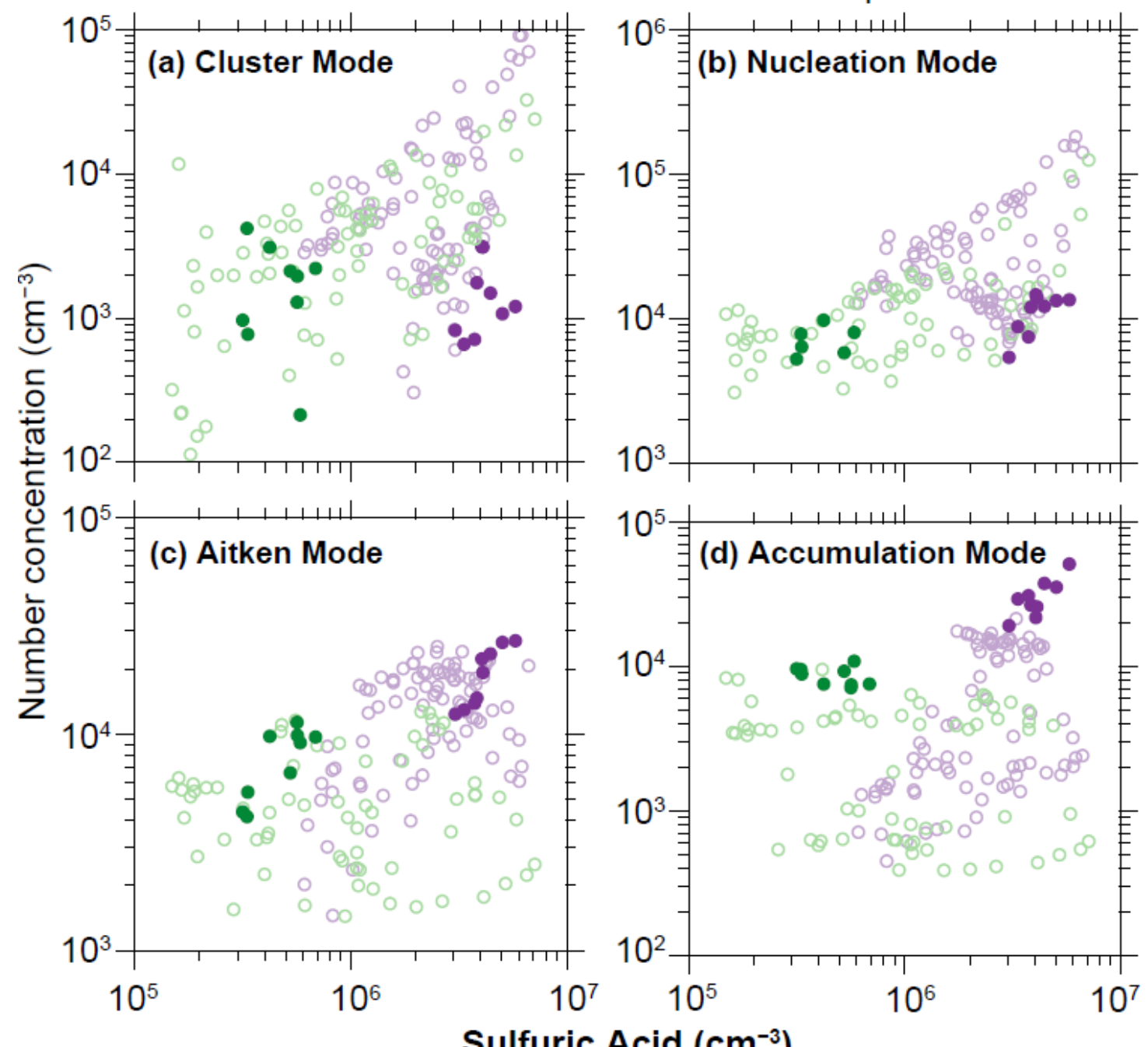

Figure 5: Number concentration of particles in cluster, nucleation, Aitken, and accumulation modes as a function of sulfuric acid concentration in 2018 and 2019, with comparison of CNY \pm 48 hours with measurements from 9pm through 5am the night of the CNY. Measurements are from BUCT-AHL. 


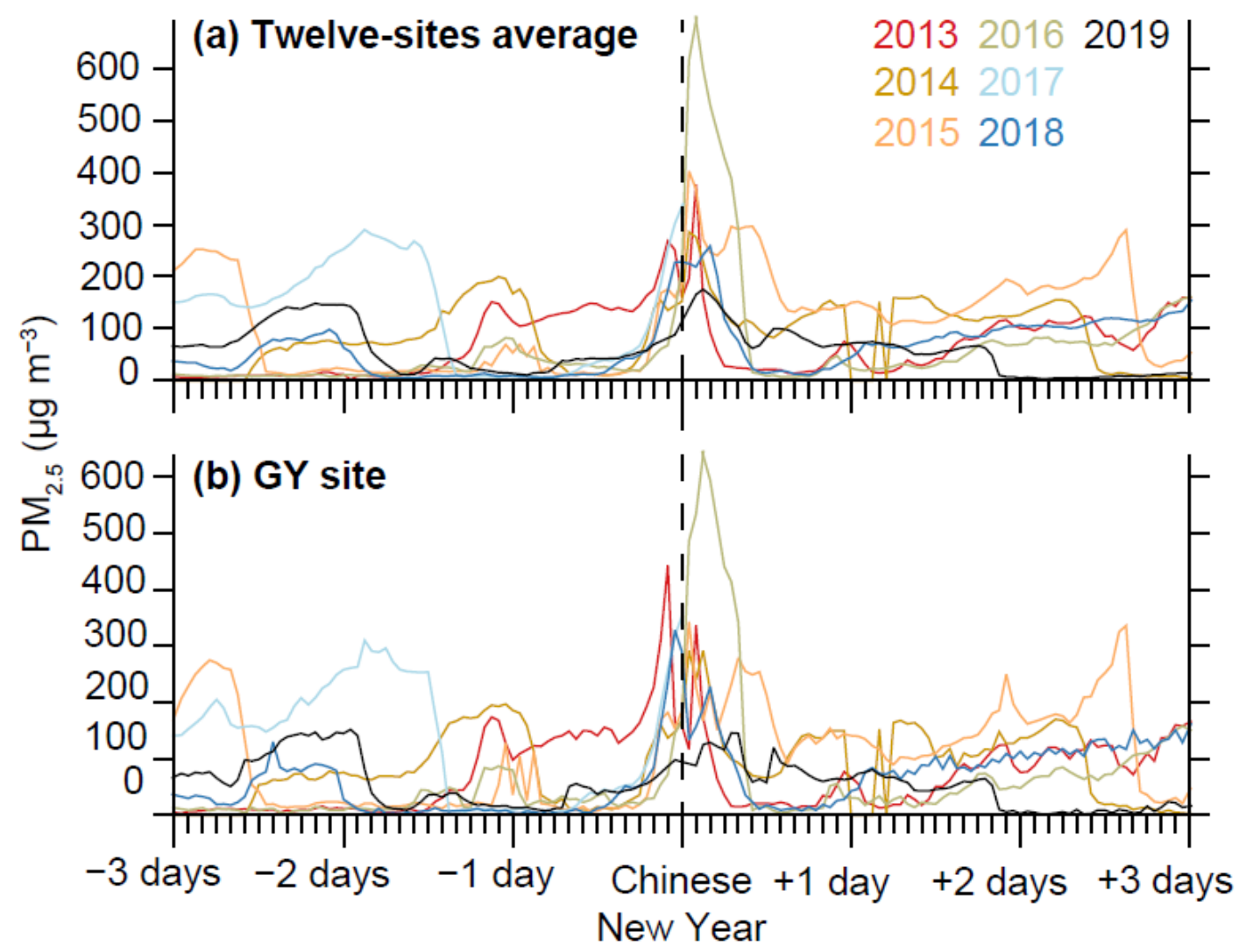

Figure 6: PM2.5 averaged from 12 MEP sites in Beijing (top) and from only the Guanyuan (GY) site, which is the closest MEP measurement site to BUCT-AHL (bottom), from three days before through three days after the 2013-2019 CNY. The highest peak of pollution during the CNY overnight was in 2016, and the lowest was in 2019. 
(a) $\mathrm{PM}_{2.5}\left(\mu \mathrm{g} \mathrm{m}^{-3}\right)$
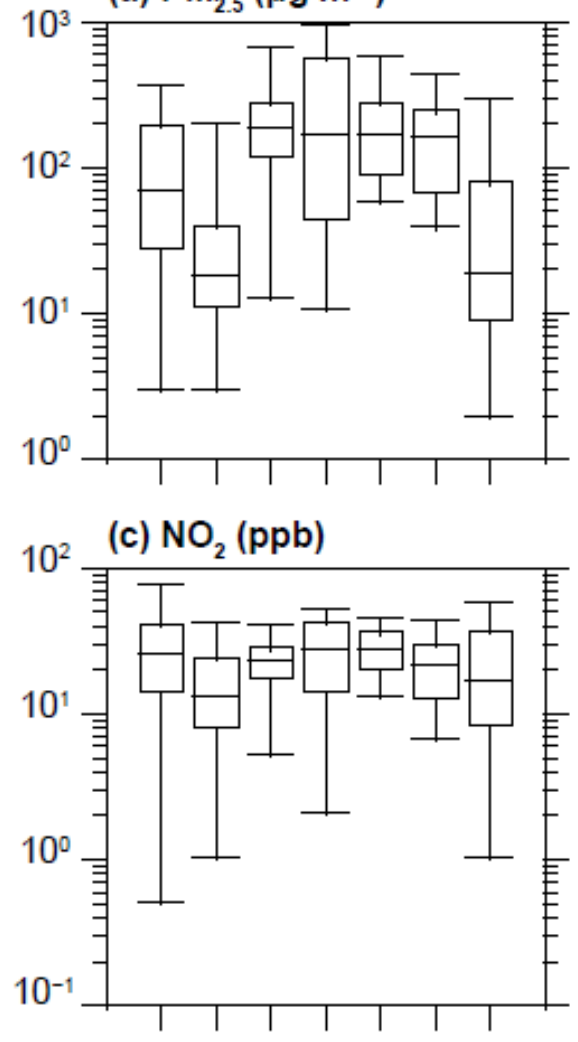

(e) $\mathrm{CO}$ (ppb)

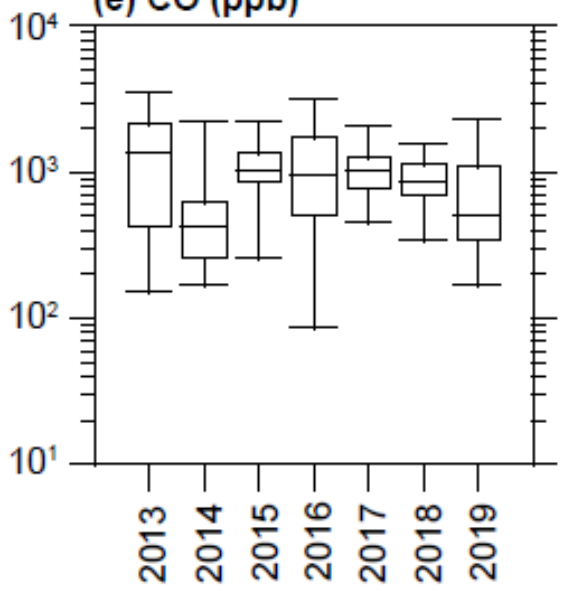

(b) $\mathrm{PM}_{10}\left(\mu \mathrm{g} \mathrm{m}^{-3}\right)$

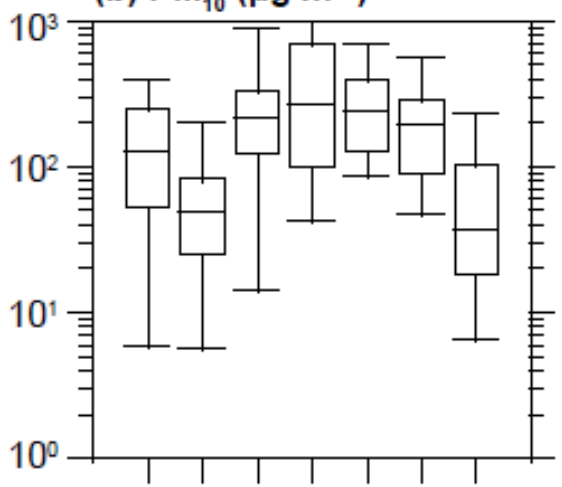

(d) $\mathrm{SO}_{2}(\mathrm{ppb})$

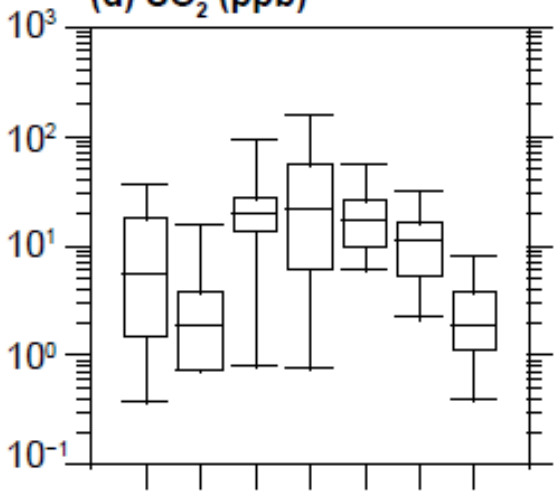

(f) $\mathrm{O}_{3}(\mathrm{ppb})$

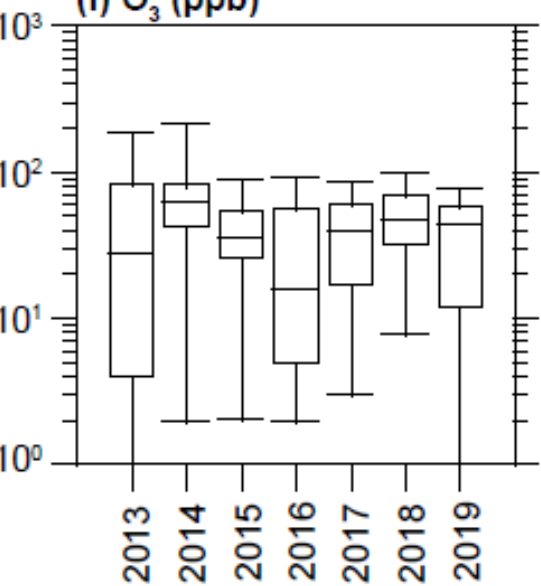

Figure 7: Boxplots of particulate matter and trace gases between 18:00 and 06:00 on the night of the Chinese New Year in the years $2013-2019$. boxplots show $1^{\text {st }}, 25^{\text {th }}, 50^{\text {th }}, 75^{\text {th }}$, and $99^{\text {th }}$ percentiles of the data across the 599 


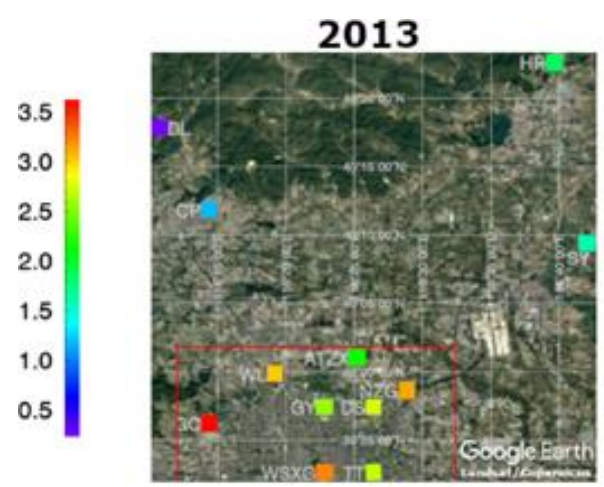

2015

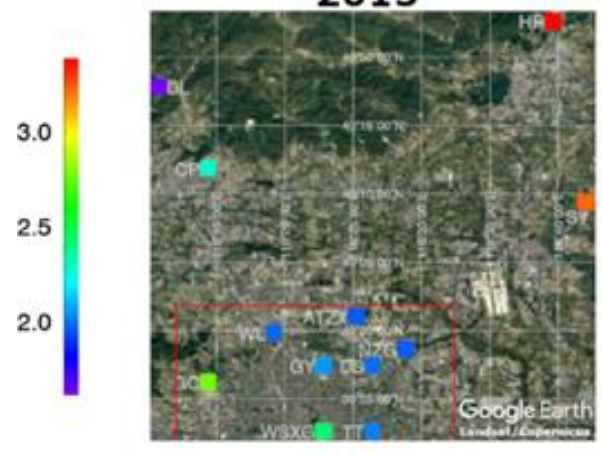

2018

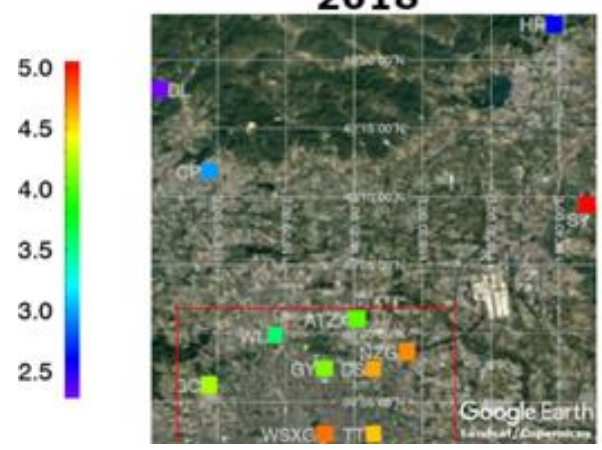

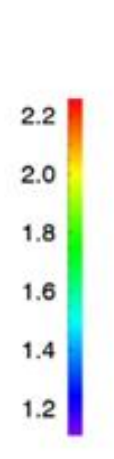
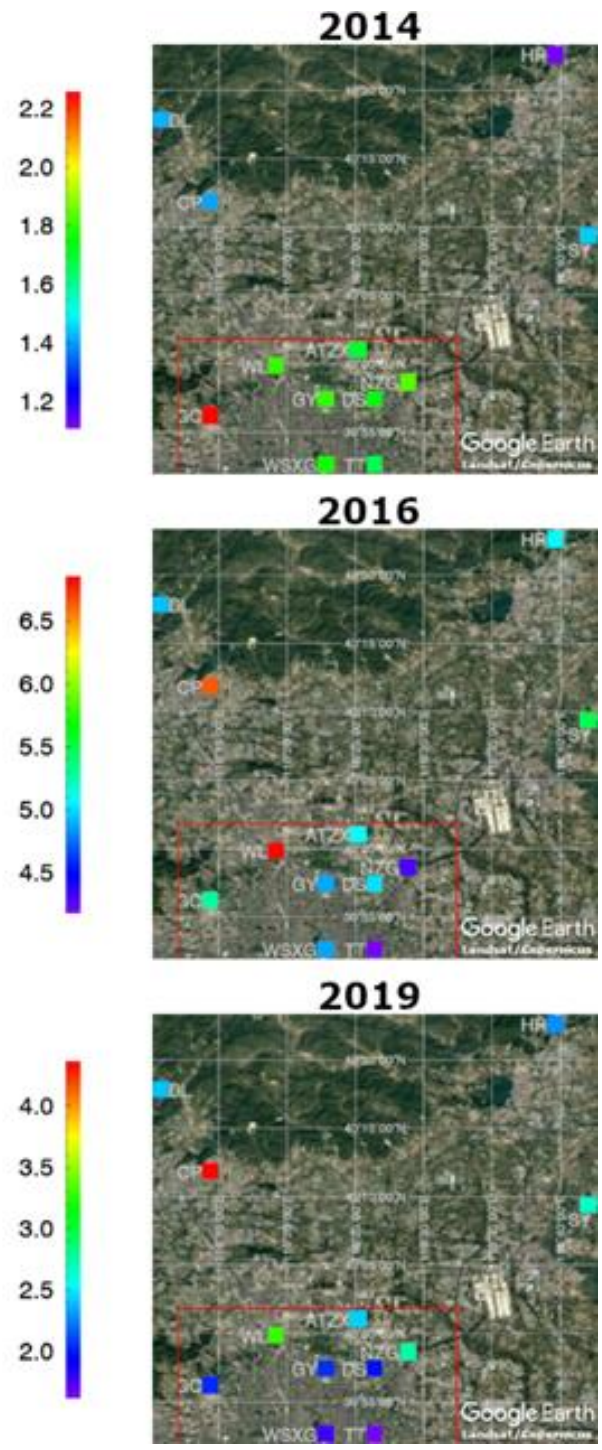

600

601

602

603

604

605

606

Figure 8: The 12 MEP sites mapped in the Beijing metropolitan area, showing the ratio of overnight $\mathrm{PM}_{2.5}$ observations during the CNY (21:00-05:00) to all data during the period of 48 hours before through 48 hours after the CNY. The red line marks the approximate location of the $5^{\text {th }}$ Ring Road. Note that the colorbars in each map are relative to only that year, and the colorbar range is not the same in different years. 2017 is omitted from this figure because data after 00:00 was not available. (C) Google Earth 


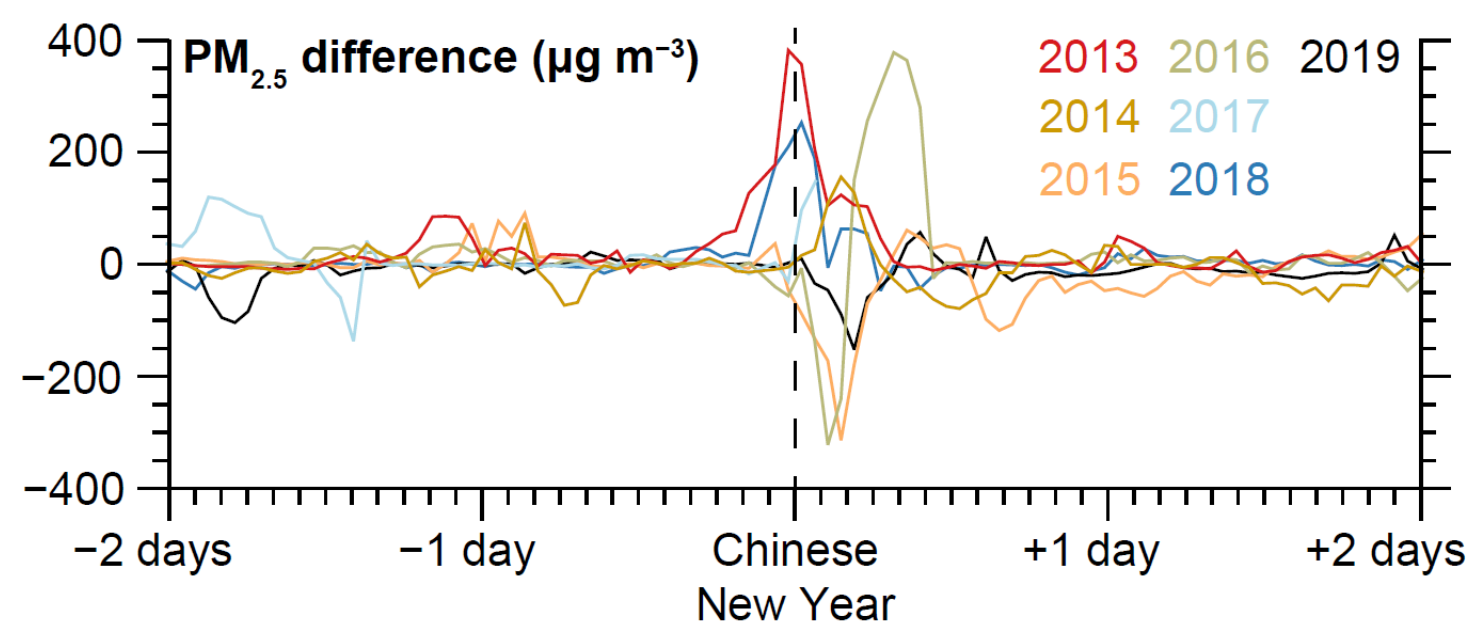

607

608

609

610

Figure 9: Differences of $\mathrm{PM}_{2.5}$ inside vs. outside the $5^{\text {th }}$ Ring Road of Beijing from 2013 through 2019. 